\title{
Hva er dialektisk atferdsterapi? En kort oversikt
}

Lars Mehlum og Anita Johanna Tørmoen

\begin{abstract}
Dialektisk atferdsterapi (DBT) er en empirisk validert behandlingsmetode for personer med kronisk suicidalitet, selvskading og emosjonelt ustabil personlighetsforstyrrelse. DBT antar at emosjonell reguleringssvikt er underliggende årsak til dysregulert atferd, og kombinerer en kognitiv-atferdsorientert tilnærming med valideringsterapi. Behandlingen er prinsippstyrt og delvis manualbasert, og inneholder flere modaliteter. Denne artikkelen gir en kort introduksjon til behandlingen og en oppsummering av evidensbasen for DBT i sin opprinnelige form. DBT er etterhvert tatt i bruk overfor andre tilstander og forsøkt benyttet med bare utvalgte deler av behandlingen, og vi ser på evidensen for slike tilpasninger. Enkelte uformelle og formelle evalueringer av de økonomiske aspektene ved DBT er rapportert og gjengis her, og vi diskuterer kort DBTs mulige fortrinn i forhold til andre behandlingsformer.
\end{abstract}

Dialectical behaviour therapy (DBT) is an evidence-based treatment for adults with repeated self-harm and borderline personality disorder and for self-harming adolescents with traits from the disorder. The assumption that a core problem of regulating emotions leads to dysregulated behaviour informs the treatment which consists of elements from cognitive-behavioural techniques and validation. The treatment is principle-driven and partially manual based. This paper intends to provide a brief introduction to DBT and lists the evidence for the full treatment programme as well as some of the literature on adaptions. Finally we discuss economic evaluations as well as DBT in relation to other evidence based treatments for borderline personality disorders.
Dialektisk atferdsterapi (dialectical behaviour therapy (DBT)) er en variant av kognitiv atferdsterapi som ble utviklet på 1980-tallet av den amerikanske psykologen Marsha M. Linehan ved University of Washington i Seattle. Behandlingsmetoden ble opprinnelig utviklet for kvinner med kronisk suicidalitet og Emosjonelt Ustabil Personlighetsforstyrrelse (EUP) (Linehan, Heard, \& Armstrong, 1993), men har siden også blitt tatt i bruk for personer med en rekke typer av alvorlige psykiske lidelser der problemer med regulering av emosjoner står sentralt. DBT har hittil med hell blitt brukt for pasienter med rusavhengighet, overspisingslidelse og depresjon og hos pasienter med komorbide tilstander slik som EUP kombinert med posttraumatisk stresslidelse. DBT i sin originalversjon ble utviklet til bruk i en poliklinisk og allmennpsykiatrisk setting, men er siden også blitt tatt i bruk blant annet i psykiatriske dag- og døgnavdelinger, i barneverninstitusjoner og i fengselshelsetjeneste. DBT brukes i dag både overfor barn, familier, ungdommer, voksne og eldre.

DBT er en prinsippstyrt, delvis manualbasert behandlingsmetode som gir behandlere retningslinjer og gode redskap i møtet med mennesker med ulike former for emosjonell reguleringssvikt, selvskading og selvmordsforsøk. Grunnleggende antakelser i DBT er at mennesker med EUP mangler ferdigheter i å regulere følelser, atferd og mellommenneskelige relasjoner og ferdigheter i å holde ut eller tolerere emosjonell smerte. En antar også at personer med EUP hindres av personlige og miljømessige faktorer i å få brukt de ferdighetene de faktisk har. Gjennom klinisk erfaring og kliniske studier fant Linehan og hennes medarbeidere at standard kognitiv atferdsterapi ikke møtte disse pasientenes behov i tilstrekkelig grad.
De tilførte derfor flere behandlingsteknikker og -prinsipper, og oppnådde med dette en markant bedre effekt på pasientgruppen.

Et sentralt prinsipp i DBT er å balansere behandlingsstrategier som kommuniserer aksept og validering med strategier for å oppnå endring. Det anses som avgjørende å kunne ivareta denne balansen i all kontakt med pasienten og gjennom hele behandlingsforløpet. Pasienter med EUP og emosjonell reguleringssvikt vil nettopp på grunn av sine problemer med å regulere forholdet til andre mennesker (inklusiv behandlere) og holde ut eller tolerere emosjonell smerte ellers lett kunne droppe ut av behandlingen. I DBT integreres kunnskap fra dialektisk og østlig filosofi med atferdsterapi, kognitiv terapi og læringsteori. Dialektikken handler om å ta hensyn til og balansere ulike deler av virkeligheten, se at ulike sannheter kan sameksistere, bruke ulike strategier og løsninger, og tenke både/og istedenfor enten/eller. Sentralt står balansen mellom det å akseptere og det å forandre - det gjelder for terapeut så vel som for pasient. Skal man klare denne balansegangen må man være våken nok i øyeblikket til å kunne registrere det som skjer mens det skjer, få tenkt seg om og få brukt sine problemløsningsferdigheter. Derfor anses det å oppøve evnen til oppmerksomt nærvær eller mindfulness som avgjørende. Linehan og DBT var først ute med å ta i bruk mindfulness som integrert del av psykoterapi. I mindfulness-øvelsene i DBT lærer både pasienter og behandlere å styre sin egen oppmerksomhet og oppleve øyeblikket på en ikke-dømmende, tolererende måte: Legge merke til og konstatere hva som faktisk skjer, verken kjøre rundt på "autopilot" eller være oppslukt av frykt for hva som skal skje eller ikke burde skjedd. 


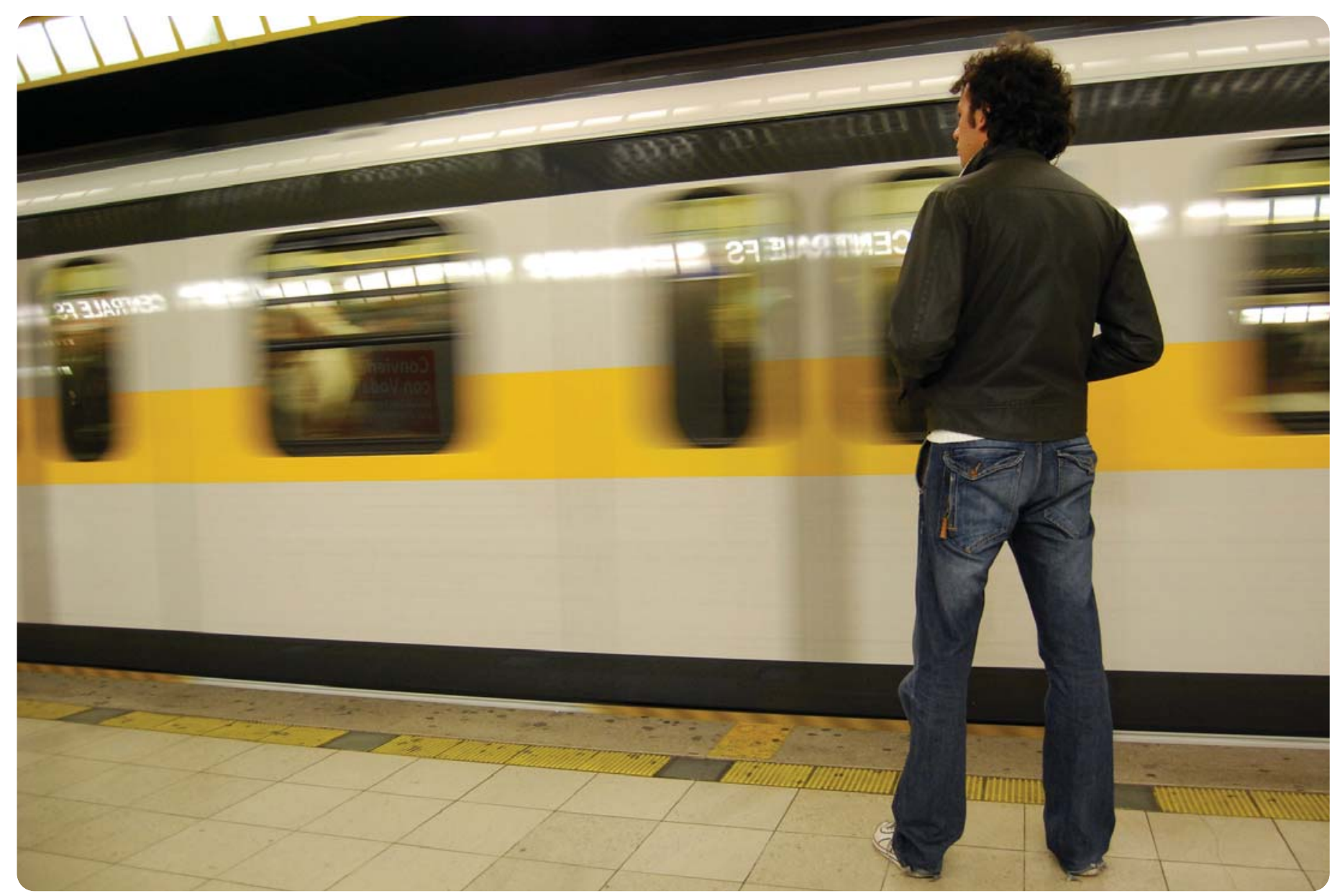

A se hvordan virkeligheten faktisk er, gjør det mulig å planlegge, ta valg og oppnå effektiv endring.

DBT er en multimodal behandling der de viktigste elementene er individualterapi og ferdighetstrening i gruppe. I standard DBT gis begge disse behandlingselementene ukentlig. Mellom gruppemøtene og individualtimene kan pasienten etter avtale kontakte sin behandler per telefon for veiledning i bruk av ferdigheter i krevende situasjoner i stedet for å ta sitt eget liv eller ty til problematferd som selvskading eller rusbruk. Telefonveiledning er en av flere strategier som benyttes for å hjelpe pasientene til å bruke ferdighetene i hverdagen og ikke bare i behandlingssammenheng. Et annet sentralt element i DBT er at behandlere som er involvert i programmet samarbeider i team såkalte konsultasjonsteam - som vanligvis møtes ukentlig. Her støtter og veileder behandlerne hverandre og hjelper hverandre til å holde et dialektisk fokus i behandlingen, styrke motivasjonen for å gi god behandling og øke egne ferdigheter $\mathrm{i}$ behandlingsmetoden.

\section{Evidensbasen for DBT}

DBTs evidensbase er omfattende, og det pågår stadig ny forskning både på den opprinnelige modellen og nyere modifikasjoner. Det er hittil publisert 16 randomisert kontrollerte studier (RCT) om effekten av standard DBT eller en av tilpasningene. De viser at DBT har god effekt på suicidal atferd/selvskading (Priebe et al., 2012; Linehan, Armstrong, Suarez, Allmon, \&t Heard, 1991; Koons et al., 2001; Linehan et al., 1993; Linehan et al., 2006; McMain et al., 2009; Van Den Bosch, Koeter, Stijnen, Verheul, \&t Van Den Brink, 2005; Verheul et al., 2003; Carter, Willcox, Lewin, Conrad, \& Bendit, 2010; Clarkin, Levy, Lenzenweger, \& Kernberg, 2007; McMain, Guimond, Streiner, Cardish, \&t Links, 2012; Feigenbaum et al., 2012), rusmisbruk (Clarkin et al., 2007; Linehan et al., 1999; Linehan et al., 2002), bulimi (BN)(Safer, Telch, Et Agras, 2001; Hill, Craighead, \& Safer, 2011), (Telch, Agras, Et Linehan, 2001) og depresjon (Van, Jeffrey, \&t Katz, 2013; Lynch, Morse, Mendelson, \& Robins, 2003). Enkelte studier viser også at DBT er kostnadseffektivt sammenlignet med vanlig behandling (Brazier et al., 2006). DBT øker pasientenes etterlevelse av behandlingen, øker pasientenes livskvalitet, reduserer antall innleggelser og legevaktbesøk og gir redusert medisinsk alvorsgrad ved selvmordsfors $ø$.

En rekke andre klinisk interessante studier har også vist at DBT har effekt for anoreksi (Salbach-Andrae, Bohnekamp, Pfeiffer, Lehmkuhl, \&t Miller, 2008), voldsatferd (Evershed et al., 2003), ADHD (Knouse, Cooper-Vince, Sprich, \&t Safren, 2008), bipolar lidelse hos ungdommer (Goldstein, Axelson, Birmaher, \&t Brent, 2007), opposisjons- eller trassforstyrrelse (Marco, Garcia-Palacios, \&t Botella, 2013) og i fengselsinstitusjoner (Nee \&t Farman, 2005). 
I Linehans første RCT (Linehan et al., 1991) ga DBT bedre resultater enn kontrollbehandlingen for alle områder som DBT fokuserer på: Reduksjon av suicidalitet/selvskade (frekvens + alvorsgrad), høyere grad av gjennomføring av behandling (83 \% vs. $42 \%$ ), redusert antall innleggelser, økt global og sosial tilpasning, samt reduksjon i sinne, depresjon, håpløshet og selvmordstanker. Ved oppfølging ett år senere ga DBT fortsatt best resultat (Linehan et al., 1993). For å undersøke om disse gunstige resultatene kunne skyldes at DBT-terapeutene var mer erfarne eller hadde høyere grad av ekspertise enn de som ga vanlig behandling ble studien replikert i 2006 med pasienter som mottok behandling av eksperter på EUP som kontrollgruppe (Linehan et al., 2006). Også her ga DBT best resultat for selvmordsforsøk (frekvens + alvorsgrad), fullføring av behandlingen (75 \% vs. $41 \%$ ) og antall innleggelser. Ytterligere RCT'er som er utført blant kronisk suicidale pasienter med EUP har vist liknende resultater.

Selvskading og suicidalitet blant ungdom er et omfattende problem i mange land, og hittil har det vært meget sparsom tilgang på intervensjoner som har vist seg effektive. DBT er blitt tilpasset til bruk for suicidale og selvskadende ungdommer av Rathus og Miller (Miller, Rathus, \& Linehan, 2007) blant annet ved å trekke med foresatte i ferdighetstreningsgruppene og ved å forkorte behandlingen fra 12 måneder til 4-5 måneder. En rekke ukontrollerte studier av DBT gitt til ungdommer er blitt publisert (Groves, Backer, van den Bosch, \&t Miller, 2012). Men den første og hittil eneste fullskala RCT av DBT for ungdommer ble utført av vår gruppe $i$ et samarbeid med barne- og ungdomspsykiatriske poliklinikker i Oslo (Mehlum et al., 2014). Resultatene av denne studien viser at 19 uker med DBT var signifikant mer effektiv enn vanlig BUP-behandling i tilsvarende periode i å redusere selvskading, selvmordstanker og depresjonssymptomer.

En modifikasjon av DBT til bruk for rusmisbrukere med EUP er testet i to RCT'er. Den første viste at DBT ga større reduksjon i narkotikabruk og større bedring i global og sosial tilpasning sammenlignet med vanlig behandling (Linehan et al., 1999). Den andre sammenlignet DBT med valideringsterapi kombinert med et tolvstegsprogram (Linehan et al., 2002). Her ga begge behandlinger signifikant bedring, mens DBT ga bedre vedlikehold av fremskritt som var oppnådd i de fire siste månedene av behandlingen.

DBT har primært fokus på endring av atferd. Kritikere har hevdet at dette bare endrer symptomene og ikke de underliggende problemene eller selvbildet. En nyere studie fra Linehan-gruppen (Bedics, Atkins, Comtois, \& Linehan, 2012) viste at dette ikke stemmer. Sammenlignet med behandling av eksperter på EUP ga DBT utvikling av et mer positivt introjekt (internalisert selvbilde), inkludert signifikant mer selvbekreftelse, kjærlighet til seg selv og selvbeskyttelse, og mindre selvkritikk, i både behandlings- og oppfølgingsperioden (1 år + 1 år).

\section{DBT kan føre til reduserte samfunnsmessige kostnader}

I løpet av de siste 10-20 år er det utført mange uformelle kvalitetssikringsstudier så vel som formelle evalueringer av DBT. Disse gir ytterligere støtte for at DBT har god effekt i vanlig klinisk rutinepraksis. For eksempel oppnådde en klinikk i New Hampshire, USA, signifikant klinisk bedring for 14 pasienter det året DBT ble tilbudt - og en kostnadsreduksjon med i gjennomsnitt \$26 571,- per pasient (American Psychiatric Association, 1998). Ved en ungdomsinstitusjon i delstaten Washington i USA ga ett års DBT signifikant mindre tilbakefall enn tidligere behandling og økonomiske besparelser på \$31 243,per ungdom (Aaos, Lieb, Mayfield, Miller, \& Pennuci, 2004). Flere andre studier har vist lignende resultater. Noen av dem viser også at pasienter som får et andre år med DBT oppnår signifikant økt produktivitet (f.eks. i lønnet arbeid, studier) og tro på egen mestringsevne (Elwood, Comtois, Holdcraft, \&t Simpson, 2007; Barley et al., 1993). At DBT reduserer de samlede utgiftene til pasientbehandling henger $\mathrm{i}$ første rekke sammen med redusert antall og varighet av innleggelser. Også antallet legevaktbesøk reduseres ofte. Standard DBT gis poliklinisk, og det arbeides målrettet for å øke pasientens evne til å klare seg hjemme i hverdagen.

\section{Implementering av hele be- handlingsprogrammet eller bare deler}

Studier tyder på at behandlingsopplegg som inneholder alle modalitetene i standard DBT, og der terapeutene gjennomfører behandlingen slik den er beskrevet, har bedre effekt enn opplegg som prøver å implementere bare noen deler av behandlingen. Det er hittil ikke publisert noen studier som har vist at det å tilby bare enkelte deler gir like god effekt som standard DBT i den populasjonen metoden opprinnelig ble utviklet for. Bruk av elementer av DBT $\mathrm{i}$ behandling av ulike populasjoner og settinger er studert i flere RCT'er og andre typer studier (Safer, Robinson, Et Jo, 2010; Lynch et al., 2007; Safer et al., 2001; Telch et al., 2001; Eric Trupin, David Stewart, Brad Beach, \& Lisa Boesky, 2002; Bradley \&t Follingstad, 2003; Chen, Matthews, Allen, Kuo, \& Linehan, 2008; T Wasser, Tyler R, Mcllhaney, Taplin R, \&t Henderson L, 2008; Feldman, Harley, Kerrigan, Jacobo, \&t Fava, 2009; Iverson, Shenk, \&t Fruzzetti, 2009; Shelton, Sampl, Kesten, Zhang, \&t Trestman, 2009; Soler et al., 2009; Sakdalan, Shaw, \&t Collier, 2010; Waltz, Landes, \& Collier, 2010; Williams, Hartstone, \&t Denson, 2010; Hill et al., 2011; Hirvikoski et al., 2011; Rizvi, Dimeff, Skutch, Carroll, \&t Linehan, 2011; Neacsiu et al., 2014; James, Winmill, Anderson, Et Alfoadari, 2011). En sammenstilling av resultatene tilsier at ferdighetstrening uten individualterapi (der ferdighetstrenerne bruker DBTs terapeutstrategier, deltar i team og det tilbys telefonveiledning) kan ha god effekt for pasienter med diverse psykiske lidelser, vansker med følelsesregulering og relasjonsproblemer. Individualterapi uten ferdighetstrening fungerer når pasienten allerede har tilstrekkelige ferdigheter og den mest kaotiske atferden er under kontroll. 
Ved suicidalitet og selvskading og/eller komplekse eller alvorlige lidelser, ser det imidlertid ut til at standard DBT trengs for å oppnå best resultat.

De behandlingsresultatene som er oppnådd i studiene som er nevnt ovenfor er basert på at terapeutene som deltok var adherente til behandlingsmetoden, dvs. at de holdt seg til behandlingens prinsipper slik de er beskrevet i lærebøker og manualer, og at behandlerne tilbød alle deler av behandlingen. Andre publiserte og upubliserte data tyder også på at adherente terapeuter oppnår bedre resultater enn ikke-adherente terapeuter (McMain et al., 2009). Terapeutens bruk av ikke-dømmende kasus-formuleringer og ivaretakelse av den dialektiske balansen mellom akseptering og endring i en behandlingssesjon, i tråd med DBT-modellen, var assosiert med færre tilfeller av selvskading hos pasientene i påfølgende uke (Linehan et al., 1993; Bedics et al., 2012).

\section{DBT vs. andre behandlingsformer}

Også andre behandlingsformer enn DBT har vist lovende resultater for Emosjonelt Ustabil Personlighetsforstyrrelse, bl.a. mentaliseringsbasert terapi (MBT). DBT har hittil en betydelig mer omfattende evidensbase enn MBT, men enkelte studier har vist at MBT gir sammenlignbare resultater i noen populasjoner. DBT og MBT har da også flere likhetstrekk, selv om begrepsapparatet som brukes er forskjellig, og selv om de tar utgangspunkt i ulike teorier for hvordan Emosjonelt Ustabil Personlighetsforstyrrelse oppstår.

Et fortrinn for DBT framfor MBT er nettopp at det er gjennomført betydelig mer forskning på DBT. Det er publisert flere studier om effekten av DBT enn om noen annen behandlingsmodell for EUP. DBT ble i en oversiktsartikkel over psykologiske intervensjoner med empirisk støtte regnet som den eneste veletablerte, empirisk baserte behandlingen for EUP, og den eneste metoden med evidens på "nivå 1" (Chambless \& Ollendick, 2001). I det nasjonale registeret over evidensbaserte tilnærminger som administreres av amerikanske SAMHSA (Substance Abuse and Mental Health Service Administration), er DBT en av få terapiformer nevnt som evidensbasert praksis for EUP, og den med best resultat (National Registry of Evidence-based Programs and Practices, 2012). Britiske NICE guidelines nevner både DBT og MBT som behandlingsformer som kan ha effekt, men det konstateres også her at DBT har mer evidens; MBT hadde på det tidspunktet bare én studie som var med i vurderingen. Dersom det er en prioritet å redusere selvskading, anbefales DBT (NICE, 2014).

Et annet fortrinn ved DBT kan være økonomiske gevinster. Tidlige studier antydet at DBT kunne være mer kostnadseffektivt enn vanlig behandling, mens en nyere systematisk oversikt viser at DBT kan ha potensial til å være kostnadseffektivt (Linehan, Kanter, \&t Comtois, 1999; Brazier et al., 2006). En sammenligning av angitte kostnader for DBT i forhold til kostnader angitt i den publiserte RCT'en av MBT antyder at DBT gir lavere gjennomsnittlige kostnader per måned og relativt sett enda lavere totale utgifter ettersom DBT gir samme resultat på kortere tid (Bateman \&t Fonagy, 2003). Også sammenlignet med angitte kostnader for to psykodynamiske behandlingsmetoder ser DBT ut til å komme best ut (van Asselt et al., 2008). Nyere studier fra bl.a. Australia (Prendergast \& McCausland, 2007; Pasieczny \& Connor, 2011), Sverige (Perseius, Samuelsson, \&t nderssson, 2004) og USA (Aaos et al., 2004) tyder også på at DBT gir lavere kostnader enn vanlig behandling.

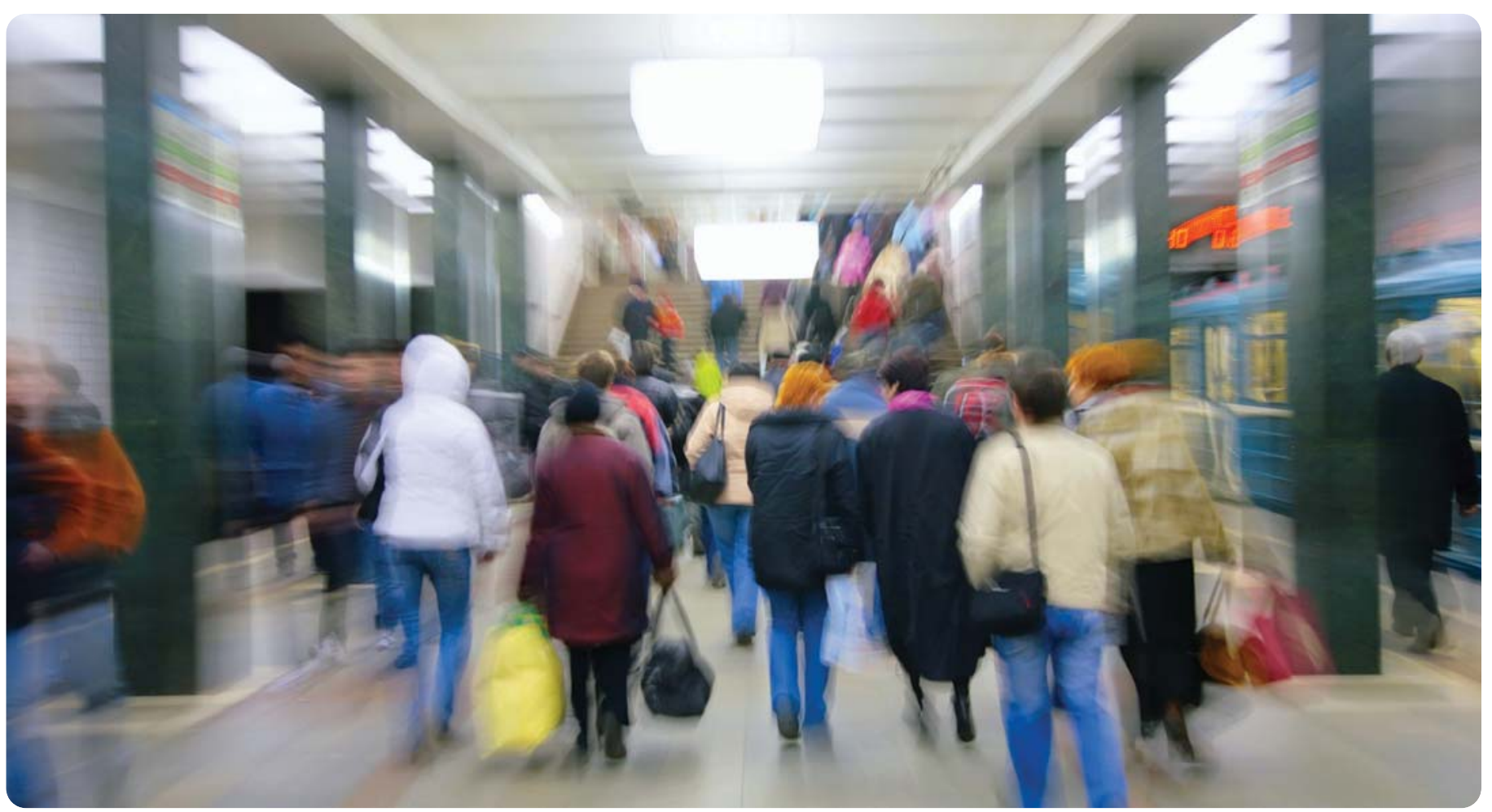


Interessant nok har flere behandlere som tilbyr MBT i USA (f.eks. McLean Hospital, Harvard, Boston og Austen Riggs Center, Massachusetts) gått inn for å kombinere MBT med DBT-basert ferdighetstrening, ettersom de opplever at MBT alene ikke har tilstrekkelig effekt på kaotisk atferd.

\section{Konklusjoner}

DBT har en solid og økende kunnskapsbase. De mange tilpasningene av metoden til nye pasientgrupper og behandlingssettinger er et positivt utviklingstrekk, men det er viktig å huske at vi fortsatt mangler empirisk evidens for en del av disse anvendelsesområdene. Vi vet heller ikke sikkert hvilke deler av behandlingen som er essensiell (uunnværlig), hvor lang varighet av behandlingen som er optimal, hvordan behandlingen egentlig virker og for hvem den virker best. Det er derfor rikelig med spørsmål som trenger forskningsmessig belysning i årene framover. For de mange som sliter med store vansker med å regulere følelser og som har et mønster av selvskading og suicidal atferd, representerer likevel DBT et godt behandlingsalternativ, og det bør tilbys til så stor del av målgruppen som mulig.

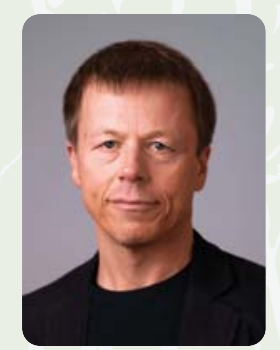

Lars Mehlum e psykiater og professor i psykiatri og suicidologi ved Universitetet i Oslo. Han er leder for NSSF og flere av senterets forskningsprosjekter, blant annet Selvskadingsstudien. Han er DBTlærer og leder for NSSFs utdanningsprogram i Dialektisk Atferdsterapi.

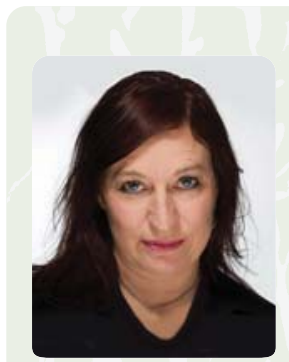

\section{Anita Johanna} Tørmoen er forsker og DBT-lærer ved NSSF. Hun har publisert flere vitenskapelige artikler relatert til selvskading og DBT. Nåværende DBT-praksis er ved Søndre Oslo DPS/OUS.

\section{Referanser}

Aaos, S., Lieb, R., Mayfield, J., Miller, M., \& Pennuci, A. (2004). Benefits and costs of prevention and early intervention programs for youth Washinton: Wash-ington State Institute for Public Policy.

American Psychiatric Association (1998). Gold award: integrating dialectical behavior therapy into a community mental health program. Psychiatr.Serv., 49, 1138-1340.

Barley, W. D., Buie, S. E., Peterson, E. W., Hollingsworth, A. S., Griva, M., Hickerson, S. C. et al. (1993). The development of an inpatient cognitive behavioral treatment program for borderline personality disorder. Journal of Personality Disorders, 7 , 232-240.

Bateman, A. \&t Fonagy, P. (2003). Health service utilization costs for borderline personality disorder patients treated with psychoanalytically orienter partial hospitalization versus general psychiatric care. American Journal of Psychiatry, 160, 169-171.

Bedics, J. D., Atkins, D. C., Comtois, K. A., \& Linehan, M. M. (2012). Weekly therapist ratings of the therapeutic relationship and patient introject during the course of dialectical behavioral therapy for the treatment of borderline personality disorder. Psychotherapy.(Chic.), 49, 231-240.

Bradley, R. G. \& Follingstad, D. R. (2003). Group therapy for incarcerated women who experienced interpersonal violence: a pilot study. J Trauma Stress., 16, 337-340.

Brazier, J., Tumur, I., Holmes, M., Ferriter, M., Parry, G., Dent-Brown, K. et al. (2006). Psychological therapies including dialectical behaviour therapy for borderline personality disorder: a systematic review and preliminary economic evaluation. Health Technology Assessment, 10, iii, ix-iii, 117.

Carter, G. L., Willcox, C. H., Lewin, T. J., Conrad, A. M., Ct Bendit, N. (2010). Hunter DBT project: randomized controlled trial of dialectical behaviour therapy in women with borderline personality disorder. Aust.N.Z.J Psychiatry, 44, 162-173.

Chambless, D. L. \& Ollendick, T. H. (2001). Empirically supported psychological interventions: controversies and evidence. Annu Rev Psychol, 52, 685-716.

Chen, E. Y, Matthews, L, Allen, C, Kuo, J. R., \& Linehan, M. M. (2008). Dialectical behavior therapy for clients with binge-eating disorder or bulimia nervosa and borderline personality disorder. Int.J Eat.Disord., 41, 505-512.

Clarkin, J. F., Levy, K. N., Lenzenweger, M. F., \& Kernberg, O. F. (2007). Evaluating three treatments for borderline personality disorder: a multiwave study. Am.J Psychiatry, 164, 922-928.

Elwood, L., Comtois, K. A., Holdcraft, L. C., \&t Simpson, T. L. (2007). Dialectical Behavior THerapy: An important component to suicide prevention. In Annual Convention of the American Association of Suicidology.

Eric Trupin, David Stewart, Brad Beach, \& Lisa Boesky (2002). Effectiveness of a Dialectical Behaviour Therapy Program for Incarcerated Female Juvenile Offenders. Child and Adolescent Mental Health, 7, 121-127.
Evershed, S., Tennant, A., Boomer, D., Rees, A., Barkham, M., \& Watsons, A. (2003). Practice-based outcomes of dialectical behaviour therapy (DBT) targeting anger and violence, with male forensic patients: a pragmatic and non-contemporaneous comparison. Crim.Behav.Ment.Health, 13, 198-213.

Feigenbaum, J. D., Fonagy, P., Pilling, S., Jones, A. Wildgoose, A., \&t Bebbington, P. E. (2012). A realworld study of the effectiveness of DBT in the UK National Health Service. Br.J Clin Psychol, 51, 121-141.

Feldman, G., Harley, R., Kerrigan, M., Jacobo, M., \&t Fava, M. (2009). Change in emotional processing during a dialectical behavior therapy-based skills group for major depressive disorder. Behav.Res Ther., 47, 316-321.

Goldstein, T. R., Axelson, D. A. M., Birmaher, B., \& Brent, D. A. (2007). Dialectical Behavior Therapy for Adolescents With Bipolar Disorder: A 1-Yea Open Trial. [Article]. Journal of American Academy of Child and Adolescent Psychiatry, 46, 820-830.

Groves, S., Backer, H. S., van den Bosch, W., \& Miller, A. (2012). Dialectical behaviour therapy with adolescents. Child and Adolescent Mental Health, 17, 65-75.

Hill, D. M., Craighead, L. W., \&t Safer, D. L. (2011). Appetite-focused dialectical behavior therapy for the treatment of binge eating with purging: a preliminary trial. Int.J Eat.Disord., 44, 249-261.

Hirvikoski, T., Waaler, E., Alfredsson, J., Pihlgren, C., Holmstrom, A., Johnson, A. et al. (2011). Reduced ADHD symptoms in adults with ADHD after structured skills training group: results from a randomized controlled trial. Behav.Res Ther., 49, 175185.

Iverson, K., Shenk, C., \&t Fruzzetti, A. (2009). Dialectical Behavior Therapy for Women Victims of Domestic Abuse: A Pilot Study. Professional Psychology: Research and Practice, 40, 242-248.

James, A., Winmill, L., Anderson, C., \& Alfoadari, K. (2011). A Preliminary Study of an Extension of a Community Dialectic Behaviour Therapy (DBT) Programme to Adolescents in the Looked After Care System. Child and Adolescent Mental Health, 16, 9-13.

Knouse, L. E., Cooper-Vince, C., Sprich, S., \& Safren, S. A. (2008). Recent developments in the psychosocial treatment of adult ADHD. Expert.Rev Neurother., 8, 1537-1548.

Koons, C. R., Robins, C. J., Lindsey Tweed, J., Lynch, T. R., Gonzalez, A. M., Morse, J. Q. et al. (2001). Efficacy of dialectical behavior therapy in women veterans with borderline personality disorder. Behavior Therapy, 32, 371-390.

Linehan, M. M., Armstrong, H. E., Suarez, A., Allmon, D., \& Heard, H. L. (1991). Cognitive-behavioral treatment of chronically parasuicidal borderline patients. Archives of General Psychiatry, 48, 10601064.

Linehan, M. M., Dimeff, L. A., Reynolds, S. K., Comtois, K. A., Welch, S. S., Heagerty, P. et al. (2002). Dialectical behavior therapy versus comprehensive validation therapy plus 12-step for the treatment of opioid dependent women meeting criteria for borderline personality disorder. Drug and Alcohol Dependence, 67, 13-26. 
Linehan, M. M., Heard, H. L., \& Armstrong, H. E. (1993). Naturalistic follow-up of a behavioral treatment for chronically parasuicidal borderline patients. Archives of General Psychiatry, 50, 971-974.

Linehan, M. M., Kanter, J., \& Comtois, K. A. (1999). DBT for borderline personality disorder: Efficacy, specificity and cost-effectiveness. In D.S.Janowsky (Ed.), Psychotherapy: Indications and outcomes (pp. 93-118). Washington DC: American Psychiatric Press. Linehan, M. M., Schmidt, H., III, Dimeff, L. A., Craft J. C., Kanter, J., \&t Comtois, K. A. (1999). Dialectical behavior therapy for patients with borderline personality disorder and drug-dependence. American Journal on Addictions, 8, 279-292.

Linehan, M. M., Comtois, K. A., Murray, A. M., Brown, M. Z., Gallop, R. J., Heard, H. L. et al. (2006). TwoYear Randomized Controlled Trial and Followup of Dialectical Behavior Therapy vs Therapy by Experts for Suicidal Behaviors and Borderline Personality Disorder. Archives of General Psychiatry, 63, 757-766

Lynch, T. R., Cheavens, J. S., Cukrowicz, K. C., Thorp S. R., Bronner, L., \&t Beyer, J. (2007). Treatment of older adults with co-morbid personality disorder and depression: a dialectical behavior therapy approach. Int.J Geriatr.Psychiatry, 22, 131-143.

Lynch, T. R., Morse, J. O., Mendelson, T., \& Robins, C. J. (2003). Dialectical behavior therapy for depressed older adults: a randomized pilot study. Am.J Geriatr.Psychiatry, 11, 33-45.

Marco, J. H., Garcia-Palacios, A., \&t Botella, C. (2013) Dialectical behavioural therapy for oppositiona defiant disorder in adolescents: a case series. Psicothema., 25, 158-163.

McMain, S. F., Guimond, T., Streiner, D. L., Cardish R. J., \&t Links, P. S. (2012). Dialectical behavior therapy compared with general psychiatric management for borderline personality disorder: clinica outcomes and functioning over a 2-year followup. Am.J Psychiatry, 169, 650-661.

McMain, S. F., Links, P. S., Gnam, W. H., Guimond T., Cardish, R. J., Korman, L. et al. (2009). A randomized trial of dialectical behavior therapy versus general psychiatric management for borderline personality disorder. American Journal of Psychiatry, 166, 1365-1374.

Mehlum, L., Tormoen, A. J., Ramberg, M., Haga, E., Diep, L. M., Laberg, S. et al. (2014). Dialectical Behavior Therapy for Adolescents With Repeated Suicidal and Self-harming Behavior: A Randomized Trial. J Am.Acad.Child Adolesc.Psychiatry, 53, 1082-1091.

Miller, A. L., Rathus, J. H., \&t Linehan, M. M. (2007). Dialectical behavior therapy with suicidal adolescents. New York: Guilford Press.
National Registry of Evidence-based Programs and Practices (2012). Dialectical Behavior Therapy SAMHSA.

Neacsiu, A. D., Lungu, A., Harned, M. S., Rizvi, S. L., \& Linehan, M. M. (2014). Impact of dialectical behavior therapy versus community treatment by experts on emotional experience, expression, and acceptance in borderline personality disorder. Behav.Res Ther., 53, 47-54.

Nee, C. \&t Farman, S. (2005). Female prisoners with borderline personality disorder: some promising treatment developments. Crim.Behav.Ment.Health, 15, 2-16.

NICE (2014). Borderline Personality Disorder:

Treatment and management. (Rep. No. 78).

Pasieczny, N. \&t Connor, J. (2011). The effectiveness of dialectical behaviour therapy in routine public mental health settings: An Australian controlled trial. Behav.Res Ther., 49, 4-10.

Perseius, K. I., Samuelsson, M., \&t nderssson, E. (2004). Does dialectical beahvioural therapy reduce treatment costs for patients with borderline personality disorder? Vård i Norden, 24, 27-30.

Prendergast, N. \& McCausland, J. (2007). Dialectical Behaviour Therapy: A 12 month Collaborative Program in a Local Community Setting. Behaviour Change, 24, 25-35.

Priebe, S., Bhatti, N., Barnicot, K., Bremner, S. Gaglia, A., Katsakou, C. et al. (2012). Effectiveness and cost-effectiveness of dialectical behaviour therapy for self-harming patients with personality disorder: a pragmatic randomised controlled trial. Psychotherapy and Psychosomatics, 81, 356365.

Rizvi, S. L., Dimeff, L. A., Skutch, J., Carroll, D., \& Linehan, M. M. (2011). A pilot study of the DBT coach: an interactive mobile phone application for individuals with borderline personality disorder and substance use disorder. Behav Ther., 42, 589600.

Safer, D. L., Robinson, A. H., \& Jo, B. (2010). Outcome from a randomized controlled trial of group therapy for binge eating disorder: comparing dialectical be-havior therapy adapted for binge eating to an active comparison group therapy. Behav.Ther., 41, 106-120.

Safer, D. L., Telch, C. F., \& Agras, W. S. (2001). Dialectical behavior therapy for bulimia nervosa. Am.J Psychiatry, 158, 632-634.

Sakdalan, J. A., Shaw, J., \&t Collier, V. (2010). Staying in the here-and-now: a pilot study on the use of dialectical behaviour therapy group skills training for forensic clients with intellectual disability. J Intellect.Disabil.Res, 54, 568-572.
Salbach-Andrae, H., Bohnekamp, I., Pfeiffer, E., Lehmkuhl, U., \& Miller, A. L. (2008). Dialectical Behavior Therapy of Anorexia and Bulimia Nervosa Among Adolescents: A Case Series. Cognitive and Behavioral Practice, 15, 415-425.

Shelton, D., Sampl, S., Kesten, K. L., Zhang, W., \& Trestman, R. L. (2009). Treatment of impulsive aggression in correctional settings. Behavioral Sciences and the Law, 27, 787-800

Soler, J., Pascual, J. C., Tiana, T., Cebria, A., Barrachina, J., Campins, M. J. et al. (2009). Dialectical behaviour therapy skills training compared to standard group therapy in borderline personality disorder: a 3month randomised controlled clinical trial. Behav.Res Ther., 47, 353-358.

T Wasser, Tyler R, Mcllhaney, Taplin R, \&t Henderson $L$ (2008). Effectiveness of dialectical behavior therapy for clients with binge-eating disorder or bulimia nervosa and borderline personality disorder. International Journal of Eating Disorders, 4, 114125.

Telch, C. F., Agras, W. S., \& Linehan, M. M. (2001). Dialectical behavior therapy for binge eating disorder. J Consult Clin Psychol, 69, 1061-1065.

van Asselt, A. D., Dirksen, C. D., Arntz, A., Giesen-Bloo, J. H., van, D. R., Spinhoven, P. et al. (2008). Outpatient psychotherapy for borderline personality disorder: cost-effectiveness of schema-focused therapy v. transference-focused psychotherapy. Br.J Psychiatry, 192, 450-457.

Van Den Bosch, L. M., Koeter, M. W., Stijnen, T., Verheul, R., \& Van Den Brink, W. (2005). Sustained efficacy of dialectical behaviour therapy for borderline personality disorder. Behaviour Research and Therapy, $43,1231-1241$

Van, D. S., Jeffrey, J., \&t Katz, M. R. (2013). A randomized, controlled, pilot study of dialectical behavior therapy skills in a psychoeducational group for individuals with bipolar disorder. J Affect.Disord. 145, 386-393.

Verheul, R., Van Den Bosch, L. M., Koeter, M. W., De Ridder, M. A., Stijnen, T., \&t Van Den Brink, W. (2003) Dialectical behaviour therapy for women with borderline personality disorder: 12-month, randomised clinical trial in The Netherlands. British Journal of Psychiatry, 182, 135-140.

Waltz, J., Landes, S. J., \& Collier, V. (2010). FAP and Dialectical Behavior Therapy. In J.Kanter, T. Mavis, \& R. J. Kohlenberg (Eds.), In The Practice of Functional Analytic Psychotherapy (pp. 47-64). New York: Springer.

Williams, S., Hartstone, M., \&t Denson, L. (2010). Dialectical Behavioural Therapy and Borderline Personality Disorder: Effects on Service Utilisation and Self-Reported Symptoms. Behaviour Change, $27,251-264$

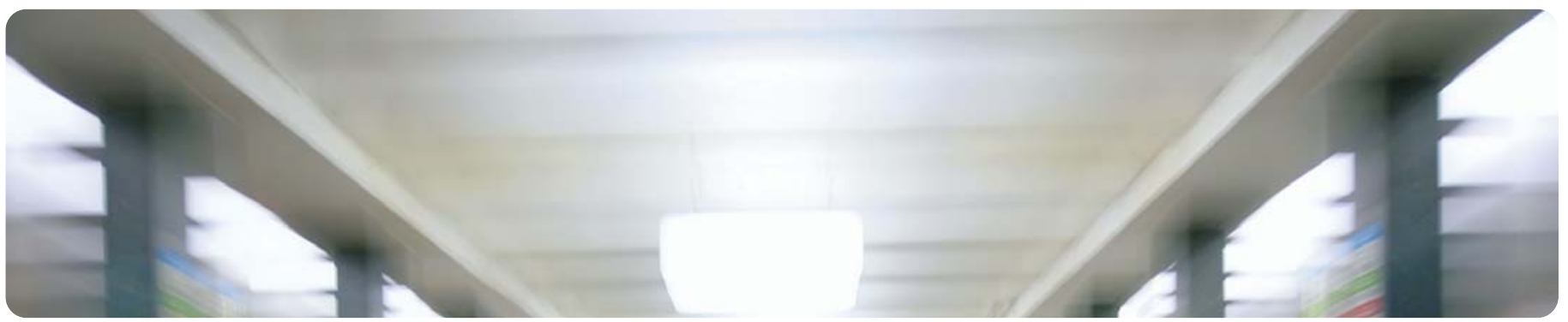

